\title{
Three new species of Hyposmocoma (Lepidoptera, Cosmopterigidae) from the Hawaiian Islands, based on morphological and molecular evidence
}

\author{
PATRICK SCHMITZ ${ }^{1} \&$ DANIEL RUBINOFF ${ }^{2.3}$ \\ Department of Plant and Environmental Protection Sciences, 310 Gilmore Hall, University of Hawaii, 3050 Maile Way, Honolulu, \\ Hawaii, 96822 USA.E-mail: ${ }^{1}$ pschmitz@hawaii.edu; ${ }^{2}$ rubinoff@hawaii.edu \\ ${ }^{3}$ Corresponding author
}

\begin{abstract}
The Cosmopterigid genus Hyposmocoma (Lepidoptera, Cosmopterigidae) is endemic to Hawaii and contains over 350 recognized species, though only one new species has been described in the past 62 years. We describe and illustrate three new species of Hyposmocoma: Hyposmocoma kaupo sp. nov. from the island of Maui, H. kapakai sp. nov. from Oahu, and H. kaikuono sp. nov. from Molokai, all known from both sexes, and all apparently single-island endemics. The casemaking larvae of all three species feed on lichen and organic debris on dry rocks in open or partly forested habitat. While morphological differences among these three species are small, genetic divergence across parts of the mitochondrial gene cytochrome oxidase I and the nuclear genes elongation factor $1 \alpha$ indicate universally deep divergence, making these taxa a classic example of sibling species.
\end{abstract}

Key words: Microlepidoptera, Cosmopterigidae, Hyposmocoma, new species, endemic, Hawaiian Islands, COI, EF1 a

\section{Introduction}

The endemic cosmopterigid moth genus Hyposmocoma, contains over 350 recognized species (Zimmerman 1978), and is one of the greatest radiations in the Hawaiian Islands, rivaling or exceeding Drosophila (Kaneshiro 1997) in endemic species diversity. Hyposmocoma are present on all the high Hawaiian Islands at almost all elevations and on many of the older and lower Northwest Hawaiian Islands where no flowing water exists (Zimmerman 1978). They occupy an extraordinary diversity of native habitats, from recent lava flows, to rainforest, to alpine scrub, and their larvae feed on a wide range of native plants, dead wood, lichens, and debris (Zimmerman 1978). Recent observations confirm that some taxa are predators (Rubinoff \& Haines 2005). Another remarkable trait of Hyposmocoma is the spectacular diversity of cases carried through larval development as shelters. Ostensibly to protect and camouflage the larvae as they feed, rest and pupate, the cases are often decorated with bits of lichen, sand, or other small objects, including feathers. Further, more than $90 \%$ of Hyposmocoma species are single-island endemics suggesting ample opportunity for isolation and radiation as compared with other groups (Gillespie \& Roderick 2002).

Butler proposed the name Hyposmochoma for a single species in 1881 in reference to the distinct subcostal hair-pencil, also called subcostal brush. Since then the correct generic name spelling of Hyposmocoma was used and later validated (Walsingham 1907; Zimmerman 1978). Because of the remarkable diversity of the genus more than 187 species names were proposed for it by Walsingham (1907) who stated that this was "[a] variable genus containing many species in a plastic state of development". Thirteen genera were proposed to encompass this diversity, but Zimmerman (1978) recognized that the synapomorphies for the 13 generic 
names were not phylogenetically robust, and he synonymized all these genera with Hyposmocoma including a total of 309 species names established by previous workers. In his excitement, Zimmerman said that: "If [he] could only find a way of doing the work, [he] would gladly devote the remainder of [his] life to the study of Hyposmocoma alone." Despite, or perhaps because of the tremendous diversity in Hyposmocoma, there has been no systematic work since Zimmerman (1978) and only one new species (Rubinoff \& Haines 2006) has been described in over 62 years since the last contribution of Swezey (1946). We have begun a systematic and phylogenetic analysis of the genus, including a significant rearing effort to establish relationships among larval case, larval ecology, habitat, and adult habitus for a wide variety of species. The following taxonomic revision is integrative (Dayrat 2005; Will et al. 2005; Rubinoff 2006) as we include a combined molecular and morphological taxonomic analysis of each species. The following represents the description of three new species found as part of this research effort.

\section{Materials and methods}

The specimens forming the basis of this study were all reared from case-making larvae. Cases of Hyposmocoma specimens collected in the field were put in Petri dishes and larvae were offered lichens, carrot and commercial fish food (TetraMin $\left.{ }^{\circledR}\right)$. For each field collection, a unique data log entry (eg. \#DR06A3) was made which includes date and location of capture, digital picture of larvae, record of larval behaviour, date of adult moth emergence, and digital picture of adult moth.

In listing the label data of the holotypes, the information is copied as found on the labels with slashes to express changes of lines and abbreviations spelled out in square brackets. For the lists of paratypes, the information is recorded without indications of line changes. For each species' holotype, the data label is printed in black on white card stock while the holotype label is hand-written in black ink on red card stock. The following acronyms are used: BPBM for Bernice P. Bishop Museum (Honolulu, USA), MHNG for Muséum d'histoire naturelle de Genève (Geneva, Switzerland), UHIM for University of Hawaii Insect Museum (Honolulu, USA), and USNM for National Museum of Natural History (Washington, D. C., USA).

Genitalia were dissected after the abdomen had macerated in a cold $20 \% \mathrm{KOH}$ solution overnight. The dissected parts were kept in lactic acid stained with orange $G$ or fuschin to stain hard tissue for descriptive purposes. Genitalia were subsequently stained with chlorazol black to stain membranes, fixed in ethyl alcohol, and mounted on slides in Euparal. The forewing and cases lengths were measured with a reticule on a stereomicroscope. The illustrations of the moths and genitalia were respectively made with a Canon D50 digital camera mounted on a Leica MZ16 stereomicroscope and an Olympus QColor3 camera mounted on an Olympus SZX10 stereomicroscope. To enhance the depth of field, images of the genitalia were stacked and reconstructed using the free available software CombineZM (http://www.hadleyweb.pwp.blueyonder.co.uk/).

The thorax of frozen moths was dissected from the body and processed following manufacturer's protocols for DNAEasy extraction kits (Qiagen, Inc). Two specimens were sequenced for $H$. kaupo, three specimens for H. kaikuono, and six specimens for H. kapakai. A total of 1,535 base pairs were sequenced from the mitochondrial gene cytochrome oxidase I (COI, 773 base pairs), and from the nuclear gene elongation factor $1 \alpha$ (EF1 $\alpha, 762$ base pairs). PCR amplification was done using for COI the primers Jerry (CAA CAT TTA TTT TGA TTT TTT GG) and Pat (TCC AAT GCA CTA ATC TGC CAT ATT A), and for EF1 $\alpha$ the primers Coma (GGC CCA GGA AAT GGG CAA AGG) and Toes (GGA GTC WCC AGC KAC GTA ACC). The amplifications were performed in a total volume of $50 \mu$. Thermal profiles for $\mathrm{COI}\left(94^{\circ} \mathrm{C}\right.$ for $1 \mathrm{~min} ; 51^{\circ} \mathrm{C}$ for $1 \mathrm{~min}$; $72^{\circ} \mathrm{C}$ for $\left.2 \mathrm{~min}\right)$, and $\mathrm{EF} 1$ a $\left(94^{\circ} \mathrm{C}\right.$ for $1 \mathrm{~min} ; 53^{\circ} \mathrm{C}$ for $1 \mathrm{~min} ; 72^{\circ} \mathrm{C}$ for $\left.2 \mathrm{~min}\right)$, started with 2 min of denaturation at $94^{\circ} \mathrm{C}$, were repeated for 34 cycles, and were followed by a final step for $12 \mathrm{~min}$ at $72^{\circ} \mathrm{C}$. Abdomens and wings were conserved in gelatine capsules as vouchers and deposited in the UHIM. Sequences are available from Genbank (accession numbers: EU812322-EU812343). 


\section{Descriptions}

Hyposmocoma kaupo Schmitz \& Rubinoff, sp. nov.

Figs 1, 4, 5-7, 14

MATERIAL EXAMINED. Holotype ox: [1] 'H[AWAI]I: East Maui, Kaupo gap Hale[akala]. N[ational]. P[ark]. | "burrito" case, I-16-04 | em[ergence], III-10-04, leg[it]. D[aniel]. Rubinoff'; [2] 'HOLOTYPE | Hyposmocoma | kaupo Schmitz \& Rubinoff'. Specimen in perfect condition except for broken antennae. Deposited in the UHIM.

Paratypes: $16 o^{x}, 11$, from Maui Island, Hawaii, USA: $-4 o^{x}$ (two dissected, slides PS118 and PS120), 2 ㅇ, same data as holotype: $10 \sigma^{\star}$ (one dissected, slide PS113), 2 ㅇ (dissected, slides PS115 and PS119), same

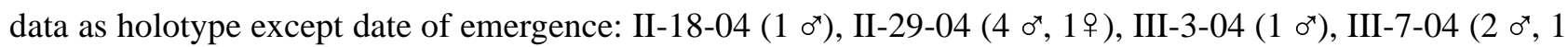
ㅇ), III-12-04 (2 ๙ $\left.^{x}\right): 2 \diamond^{\star}, 5$ ㅇ, HI: Makawao Forest Reserve, Kahakapaa trail, on rocky bank, "burrito" case,

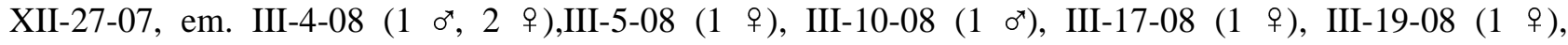
\#DR07L1A, leg. W[ill]. Haines. Deposited in BPBM, MHNG, UHIM and USNM.

Specimens sequenced: 3 specimens from Maui Island, Hawaii, USA: 2 specimens, with same data as holotype: 1 specimen, HI: Makawao Forest Reserve, Kahakapaa trail, on rocky bank, "burrito" case, XII-2707, \#DR07L1A, leg. W. Haines.

DiAGNOSIS. Among the species of Hyposmocoma, H. kaupo can be separated by its distinct colouration. It is most similar to H. montivolans (Butler, 1882), which is endemic to the island of Oahu, in size and forewing pattern, but $H$. montivolans is still larger (holotype male forewing: $14 \mathrm{~mm}$; Walsingham 1907) and the forewing ground colour is olive green whereas $H$. kaupo is greyish blue. Also it differs in male genitalia by having more than five spurlike setae on both valvae and a subapical projection on left valve which bears two spurlike setae. H. kaupo differs from H. kapakai and H. kaikuono in characters mentioned in the Diagnosis and Description of these species, below.

DESCRIPTION. MALE ( $\mathrm{n}=15$ ) (Figs 1, 4, 5-7). Wingspan 12.2-13.2 mm (Holotype: $12.7 \mathrm{~mm}$ ). Head with greyish-blue white tipped scales converging toward midline on occiput. Haustellum with greyish blue, brown tipped scales. Maxillary palpus reduced. Labial palpus recurved with greyish-blue brown tipped scales, subapicaly white ring on second segment, and slender darkish brown third segment. Antenna flagellum darkish brown; scape with scales white tipped at the end; antennal pecten present with up to eight thin setae. Thorax mostly greyish-blue; darkish brown at collar and at apex medially, with yellowish-orange scales laterally, more or less conspicuous and forming sometimes small spots; apex of tegula and outer margin of metathorax darkish brown; metascutellum greyish-beige. Foreleg coxa with off-white and greyish-blue brown tipped scales; femur, tibia, and tarsomeres mostly darkish brown with off-white ring at apex of femur, tibia, and apex of tarsomeres I-V. Midleg as foreleg, but also with ring of greyish-blue scales on tibia postmedially and extended off-white rings, spurs off-white. Hindleg as midleg. Forewing mostly greyish-blue with pale tipped scales (darker for the specimens collected in the Makawao Forest Reserve); off-white scales at jointure of wing; darkish brown markings as a basal band, a small basocostal spot not reaching dorsal margin, a medium size patch postbasally (slightly below midline), a submedial patch above midline, a larger oval submedially along posterior margin without reaching it, a medium size patch medially in middle of wing just above submedial oval, and a pair of medium patches, sometimes joined, situated postmedially, the patch below reaching inner margin; small off-white spots at $1 / 2$ and $3 / 4$ on dorsal margin, with sometimes slightly off-white markings as small dots around darkish brown markings; fringe off-white to greyish beige with darker tipped scales. Hindwing greyish brown with greyish-beige fringe. Subcostal brush conspicuous (Fig. 4), on dorsal surface on anterior margin, dark brown extending $1 / 2$ the length of hindwing. Abdomen dorsally uniform shiny grey; ventrally off-white, with tuft of long pale beige scales on each side of genitalia. Sclerotized hook arising from sclerotized ring on the right side of seventh abdominal tergum (pseuduncus sensu Zimmerman 1978), elon- 
gate, slightly curved, narrowing apically to blunt apex; minute sclerotized point on the left side. Seventh abdominal sternum with triangular fold in the middle pointing perpendicularly. Genital flaps (epiptygmata sensu Zimmerman 1978) on eighth abdominal sternum, rounded, broad, and thin.

Male genitalia (n=3) (Figs 5-7). Uncus and gnathos absent, but replaced by uncuslike processes (brachia sensu Zimmerman 1978) attached to tegumen (Zimmerman, 1978); right process elongate, curved ventrally, apically pointed, about $4 \mathrm{X}$ longer than reduced left process. Tegumen wide, heavily sclerotized, dorsoventrally flattened, ventral connection broad. Vinculum vestigial. Valvae asymmetrical, with long and slender arms adorned with setae disposed comblike along dorsal margin, broadened distally, with prominent, uniformly spaced sclerotized spurlike setae, sequentially longer distally, varying in number (six or seven, depending on specimen studied), setae shorter on right valva, left valva with subapical triangular projection adorned with two spurlike setae. Phallus slightly bent to the right, stout, blunt tipped, heavily sclerotized, curved at right angle at about 2/3 length. Anellus with asymmetrical lobes, left lobe with broad bulbous projection at middle, then terminating in short point, right lobe delicate and slightly curved, bulbous at end, both adorned with small setae, two to three very long setae on apex, $2 \mathrm{X}$ length of phallus.
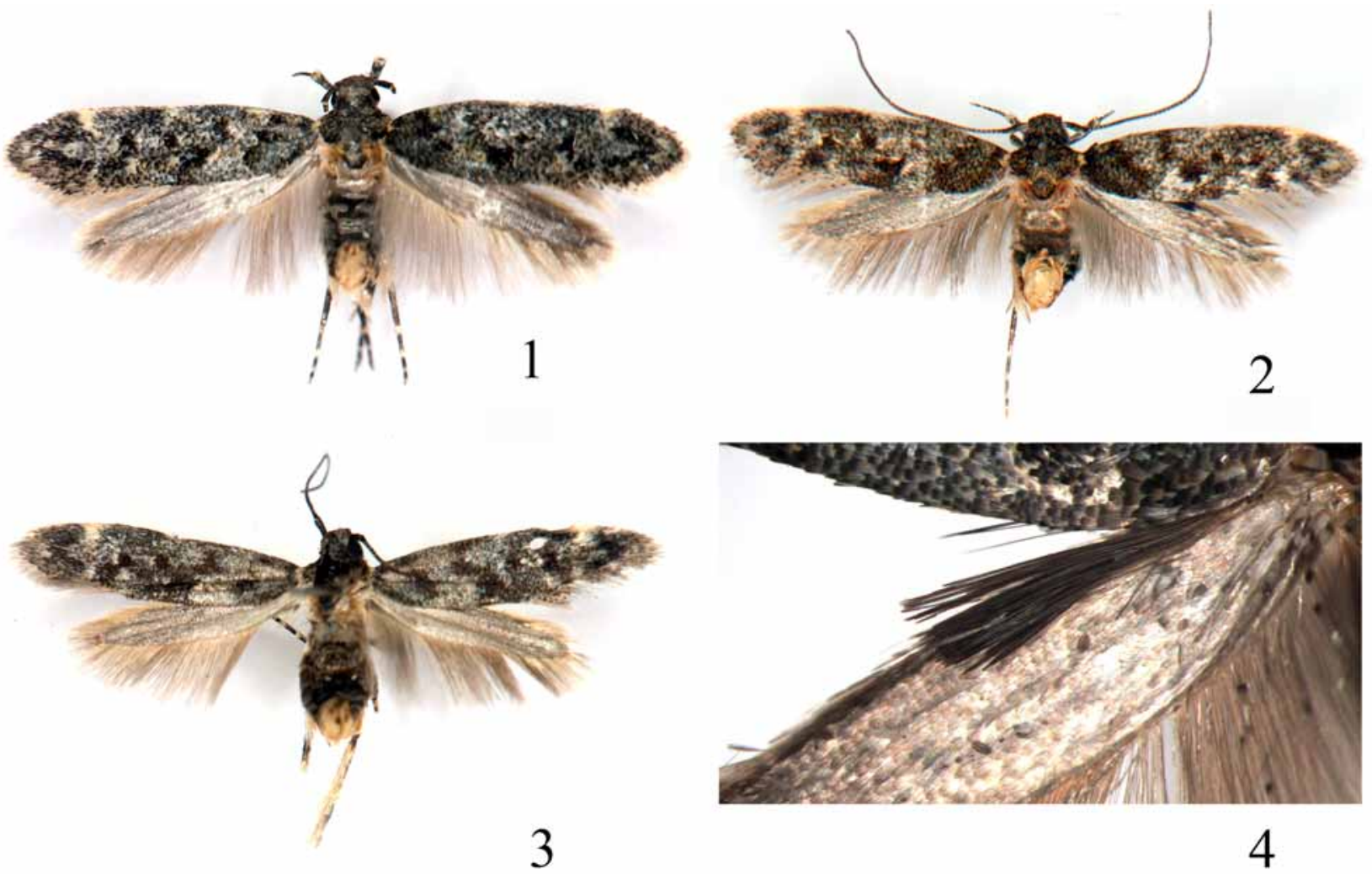

FIGURES 1-3. Holotypes of Hyposmocoma spp. 1. H. kaupo; 2. H. kapakai; 3. H. kaikuono.

FIGURE 4. Subcostal brush of Hyposmocoma kaupo.

FEMALE (n=4). Wingspan 12.4-13.3 mm. Frenulum with 3 acanthae. Antenna slightly thinner than that of male. Otherwise externally like males.

Female genitalia (n=2) (Fig. 14). Papillae anales short, lightly sclerotized and setose, slightly longer than wide, pointed lateroapically. Posterior apophyses very slender and straight, about $5 \mathrm{X}$ length of papillae anales. Anterior apophyses slightly broader and about $1 / 3 \mathrm{X}$ length of posterior apophyses. Ostium bursae heavily sclerotized, externally protruding, question-marked shaped, broad at base with sickle shaped apex. Ductus bursae short, of medium girth. Inception of ductus seminalis large, at about $1 / 3$ length of corpus bursae. Apical margin of tergum VIII with slight broad emargination medially. Corpus bursae oval and elongate, with light scobination, lightly sclerotized from about middle to pointed proximal end; signum absent. 
Larva cases $(n=68)$. Burrito-shaped structures (in reference to the shape of a type of Mexican food that consists of a flour tortilla wrapped around a filling), 4.5-8.0 mm long, large and rounded with a curved pointed distal end, decorated with bits of sand, pebbles, and lichens intricated with silk filaments. Case background colour ranges from grey to brown.

ETyMology. The name of $H$. kaupo is derived from one of the type locality situated in Haleakala National Park on the Island of Maui.

BIOLOGY. All adults were reared from case-making larvae. Larvae were collected during the day in January at an elevation of 1085 meters on lichen covered rocks in the Kaupo Gap area of east Maui. Larvae were observed feeding and were reared on lichens growing on rocks. While a few larvae were actively crawling and feeding on the rocks during the day when we were collecting, most were hidden near the base of the rocks where grass partially concealed them. Adults had already emerged from some of the cases, suggesting that the flight period may begin earlier than our collection date, and certainly earlier than the first emergences we recorded. In captivity, adults left together readily mated during the daylight hours, and females oviposited on a rock in a screened cage. Young, case-bearing larvae appeared several weeks later but were not reared. Based on this apparently continuous life cycle, this species may be homodynamic.

DiSTRIBUTION. Known only from the Hawaiian island of Maui, presumed to be endemic to east Maui. Although its range may be broader, collections from other parts of Maui have yielded genetically distant species.

REMARKS. The differences in wing size and those of the forewing colouration and details of genitalia are morphological characters useful in distinguishing H. kaupo as a distinct species. This species status is strongly supported by the divergence in two DNA fragments from COI and the much slower evolving EF1 a (Reed \& Sperling 1999) (see Table 1).

TABLE 1. Uncorrected intraspecific and interspecific genetic distances among the three Hyposmocoma species for COI (left) and EF1 a (right) fragments, with standard deviation in brackets.

\begin{tabular}{lllllll}
\hline & H. kaupo & \multicolumn{3}{c}{ H. kapakai } & \multicolumn{2}{c}{ H. kaikuono } \\
& COI & EF1 $\alpha$ & COI & EF1 $\alpha$ & COI & EF1 $\alpha$ \\
\hline H. kaupo $(\mathrm{n}=3)$ & $0.7( \pm 0.2)$ & $0.1( \pm 0.1)$ & - & - & - & - \\
H. kapakai $(\mathrm{n}=6)$ & $6.5( \pm 0.2)$ & $1.9( \pm 0.6)$ & $0.6( \pm 0.2)$ & $0.7( \pm 0.7)$ & - & - \\
H. kaikuono $(\mathrm{n}=2)$ & $5.6( \pm 0.1)$ & $1.5( \pm 0.1)$ & $5.7( \pm 0.2)$ & $0.7( \pm 0.6)$ & 0.0 & 0.0 \\
\hline
\end{tabular}

\section{Hyposmocoma kapakai Schmitz \& Rubinoff, sp. nov.}

Figs 2, 8-10, 15, 17

MATERIAl EXAmined. Holotype ơ : [1] "H[AWAI]I: Oahu, Halona blowhole | "burrito" case, II-2-08 | em[ergence], III-5-08, \#DR08B1A| leg[it]. P[atrick]. Schmitz'; [2] 'HOLOTYPE | Hyposmocoma | kapakai Schmitz \& Rubinoff'. Specimen in perfect condition except for broken right hindleg. Deposited in the UHIM. Paratypes: $8 \sigma^{x}, 11$ ㅇ, from Oahu Island, Hawaii, USA: $-3 \diamond^{x}, 4$ 우, same data as holotype except date of emer-

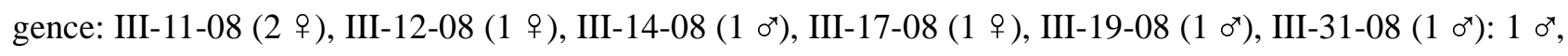
2 우, HI: Oahu, Makapu’u Point Trail, "burrito" case, I-7-06, em. I-29-06 (1 우), II-13-06 (1 ㅇ), II-25-06 (1 $\left.\circ^{7}\right)$, \#DR06A4, leg. W. Haines, M. Heddle. $50^{\star}$ (one dissected, slide PS111), 5 우 (one dissected, slide PS116), HI: Oahu, Blowhole by Sandy Beach, "burrito" case, I-7-06, em. II-6-06 (2 우), II-10-06 (3 ㅇ), II-24-06 (1 ơ), II27-06 (3 $\left.\sigma^{\top}\right)$, III-9-06 ( $\left.1 \mathrm{o}^{7}\right)$, \#DR06A3, leg. W. Haines, M. Heddle. Deposited in BPBM, MHNG, MHNG, UHIM and USNM. 
Specimens sequenced: 6 specimens from Oahu Island, Hawaii, USA: 1 specimen, same data as holotype: 2 specimens, HI: Oahu, Blowhole by Sandy Beach, "burrito" case, I-7-06, \#DR06A3, leg. W. Haines, M. Heddle: 3 specimens, HI: Oahu, Makapu'u Point Trail, "burrito" case, I-7-06, \#DR06A4, leg. W. Haines, M. Heddle.

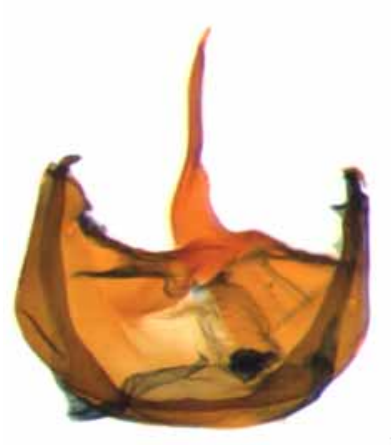

5

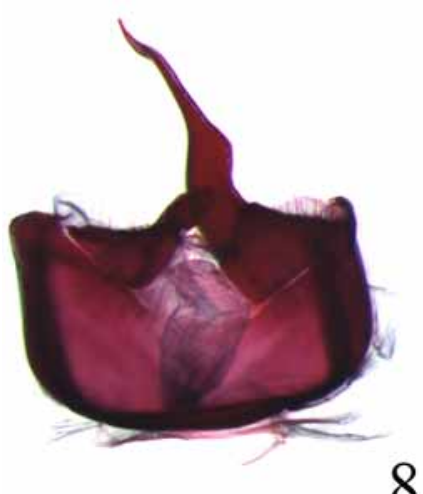

8

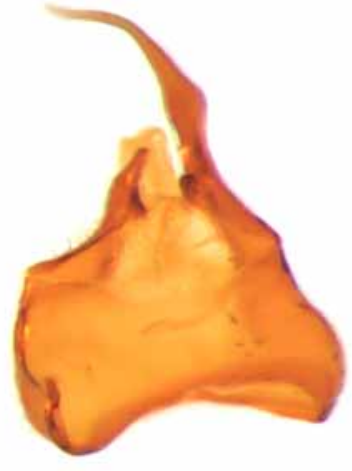

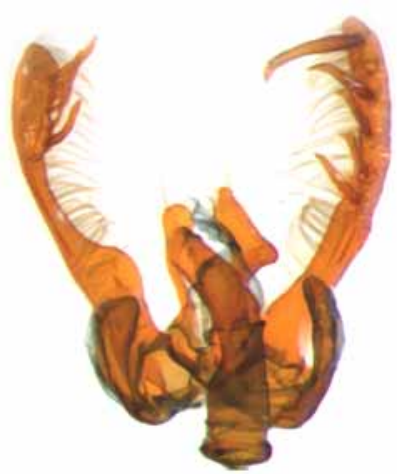

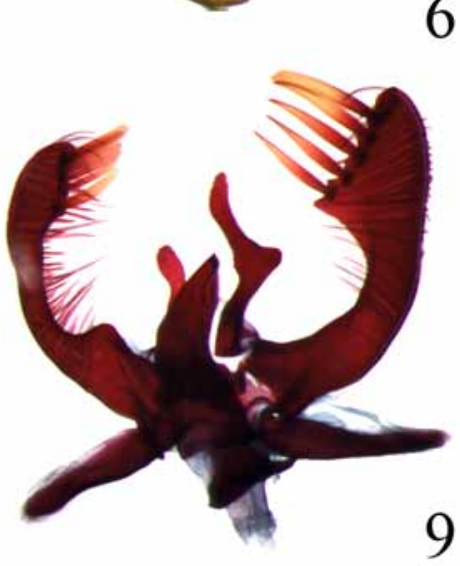

6

9
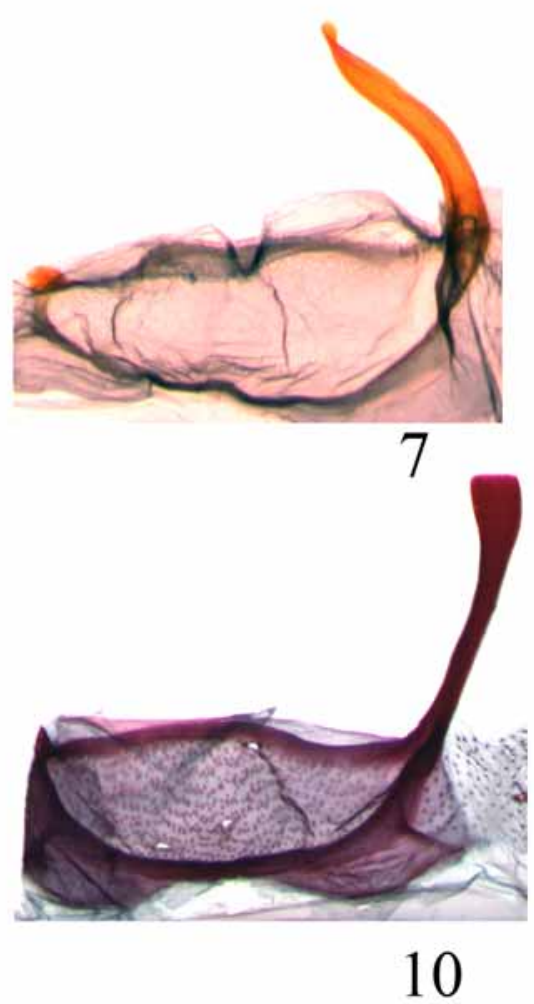
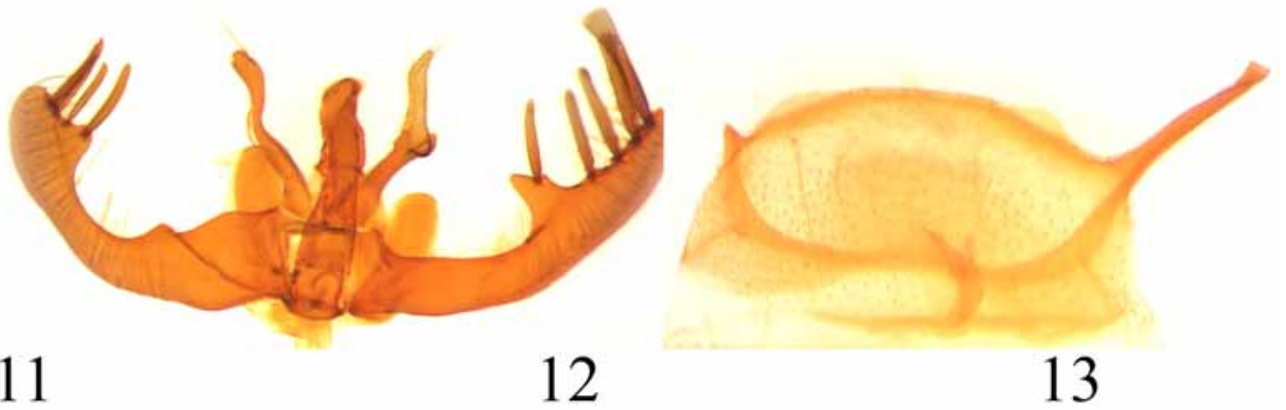

FIGURES 5-7. Male genitalia of Hyposmocoma kaupo from specimen on slide PS118. 5. Tegumen, ventral aspect; 6. Valvae with phallus, ventral aspect; 7. Sclerotized hook on abdominal segment VII, ventral aspect.

FIGURES 8-10. Male genitalia of Hyposmocoma kapakai from specimen on slide PS111. 8. Tegumen, ventral aspect; 9. Valvae with phallus, ventral aspect; 10. Sclerotized hook on abdominal segment VII, ventral aspect.

FIGURES 11-13. Male genitalia of Hyposmocoma kaikuono from specimen on slide PS140. 11. Tegumen, ventral aspect; 12. Valvae with phallus, ventral aspect; 13. Sclerotized hook on abdominal segment VII, ventral aspect.

DiAgNOSIS. $H$. kapakai is most similar in wing markings to $H$. kaikuono sp. nov., $H$. kaupo sp. nov., and H. montivolans (Butler, 1882), but it differs from H. kaupo and H. kaikuono in male genitalia by having no projection on left valva, and from $H$. kaupo in female genitalia by having a membranous rather than sclerotized corpus bursae. Also forewing background colour of $H$. kapakai differs from these species by being paler with brownish markings. 
DESCRIPTION. MALE (n=6) (Figs 2, 8-10). Wingspan 10.9-11.3 mm (Holotype: $11.1 \mathrm{~mm}$ ). As H. kaupo, except forewing, thorax, and abdomen paler; markings on forewing more brownish; antennal pecten with up to five thin setae; sclerotized hook with broad and stout apex.

Male genitalia (n=1) (Figs 8-10). As for H. kaupo, except left valva without triangular projection; six spurs on valvae more flattened dorsoventrally.

FEMALE (n=7). Wingspan 10.9-13.2 mm. Frenulum with 3 acanthae. Antenna slightly thinner than that of male. Otherwise externally like males.

Female genitalia (n=1) (Fig. 15). As for H. kaupo, except without sclerotized area on posterior half of corpus bursae; corpus bursae smaller; ostium bursae broader, apex less acute.

Larva cases ( $\mathrm{n}=87$ ) (Fig.17). The case type is a burrito-shaped structure as in H. kaupo (3.8-7.3 mm in length). The background colour of the cases ranges from beige for the specimens collected on rocks near the sand beach to greyish-brown for those collected on the rocky shoreline.

ETYMOLOGY. From the Hawaiian kapakai, or seaside, referring to the collection place of the cases of this species situated near the sea.

BIOLOGY. Adults were reared from case-making larvae collected during the day in January on the coast at sea level. Larvae were reared on fish food and carrots. Larvae were sparsely distributed along shoreline region. Parasitoids were reared from some larvae and have been identified as belonging to the Eulophidae (Hymenoptera).

DiSTRIBUTION. Currently known only from the southeast coastal region of the island of Oahu to which it is presumed to be endemic. Rearing of larvae with similar cases from upland areas of Oahu has yielded dissimilar species that we have not been able to identify.

REMARKS. The differences in wing size and those of the forewing colouration and details of genitalia are morphological characters useful in distinguishing H. kapakai as a distinct species. This species status is strongly supported by the divergence in two DNA fragments (see Table 1)..

\section{Hyposmocoma kaikuono Schmitz \& Rubinoff, sp. nov.}

Figs 3, 11-13, 16

MATERIAL EXAMINED. Holotype $\sigma^{x}$ : [1] 'H[AWAI]I: Molokai Isl[and]. | Kamehameha H[igh]w[ay]. | near Honouli, Malo'o Bay | C[oa]st. on 1[i]ch[e]n on rocks | I-02-06, em[e]rg[ence], II-17-06 | [Will] Haines, coll[ector]. Log \#DR06A1'; [2] 'HOLOTYPE | Hyposmocoma | kaikuono Schmitz \& Rubinoff'. Specimen in perfect condition except for broken right antenna and labial palpi, and small hole in right forewing. Deposited in the UHIM.

Paratypes: $2 \sigma^{x}, 11$ ㅇ, from Molokai Island, Hawaii, USA: - $10^{x}$ (dissected, slide PS110), 3 ㅇ (one dissected, slide PS117), same data as holotype: $1 \sigma^{x}, 4$ ㅇ, same data as holotype except date of emergence: II-22-

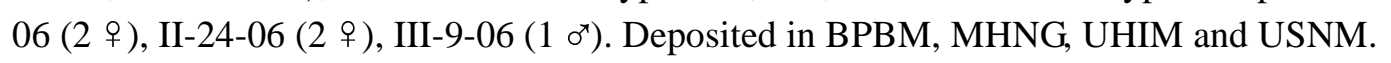

Specimens sequenced: 2 specimens from Molokai Island, Hawaii, USA, with same data as holotype.

Diagnosis. $H$. kaikuono is most similar in wing pattern to $H$. kapakai sp. nov., $H$. kaupo sp. nov., and $H$. montivolans (Butler, 1882), but it differs from H. kaupo and H. kapakai in male genitalia in having five spurlike setae on both valvae and having a subapical projection on left valve bearing only one spurlike setae $(H$. kaupo bears two spurlike setae on projection, $H$. kapakai and $H$. montivolans have no projection), and from $H$. kaupo in female genitalia by having the corpus bursae membreanous. H. kaikuono differs also from these species by having a short and thin sclerotized hook.

DESCRIPTION. MALE (n=3) (Figs 3, 11-13). Wingspan 10.1-12.1 mm (Holotype: $11.6 \mathrm{~mm}$ ). As $H$. kaupo, except forewing, thorax, and abdomen lighter; markings on forewing more brownish; antennal pecten present with seven thin setae; sclerotized hook short and thin. 

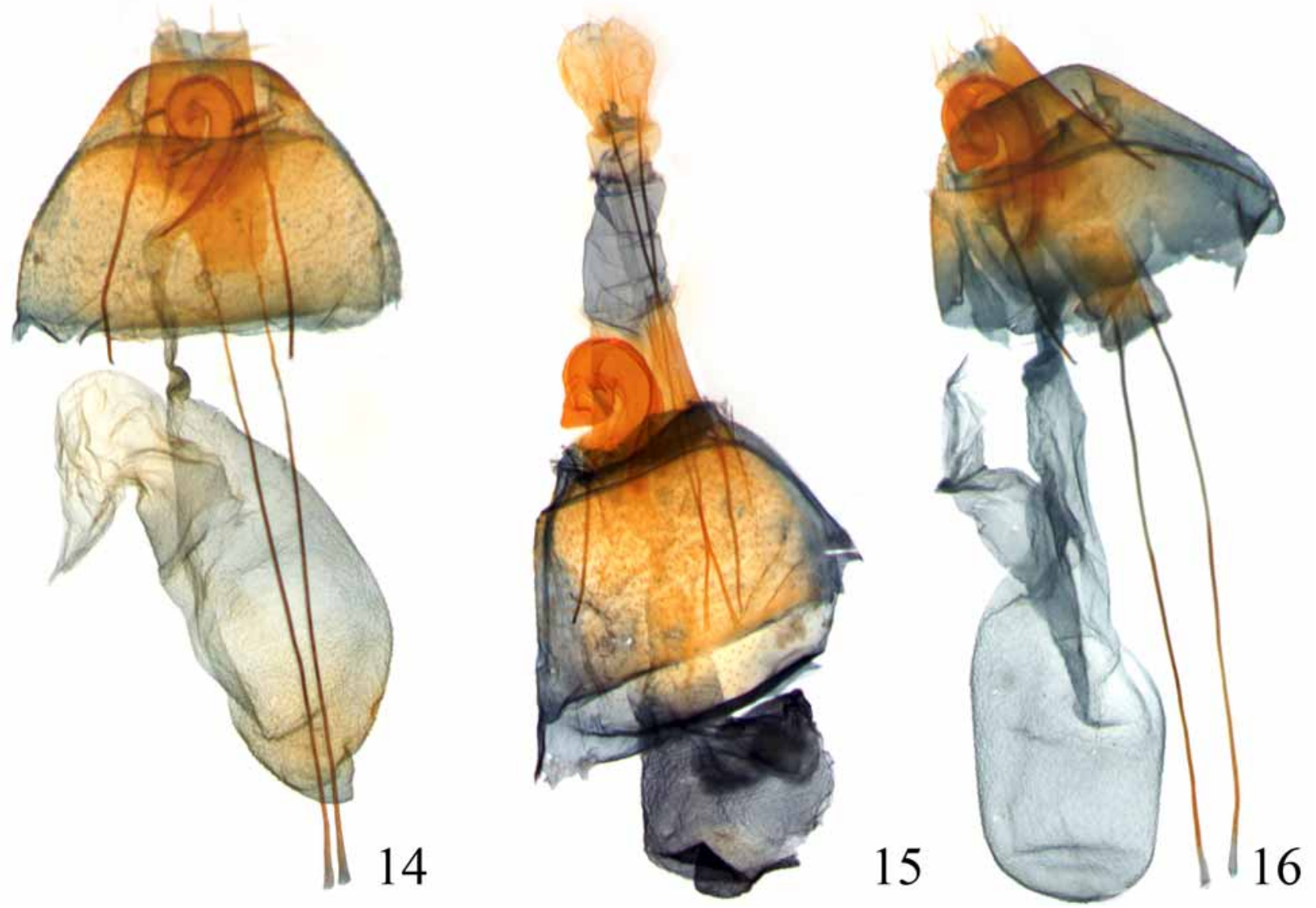

FIGURES 14-16. Female genitalia of Hyposmocoma spp., ventral aspect 14. H. kaupo (slide PS119); 15. H. kapakai (slide PS116); 16. H. kaikuono (slide PS117).

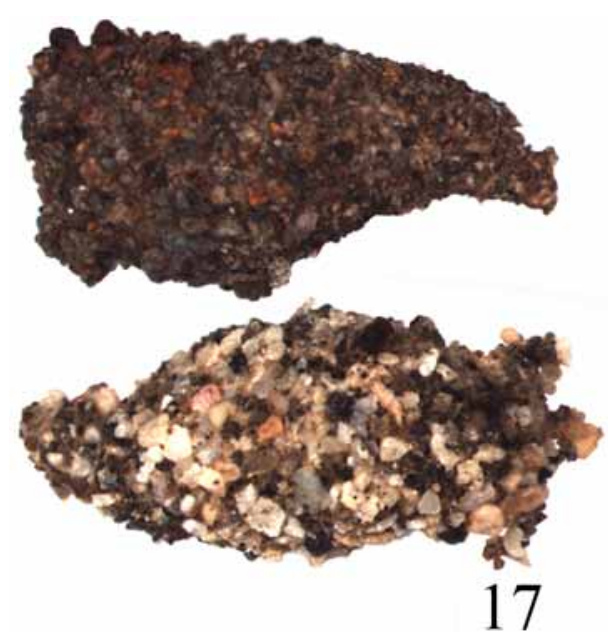

FIGURE 17. Case types of Hyposmocoma kapakai from specimens collected from Makapu'u (top) and Sandy Beach (bottom).

Male genitalia (n=2) (Figs 11-13). As for H. kaupo, except five spurlike setae on valvae; left valva with subapical projection bearing one of the spurlike setae.

FEMALE $(\mathrm{n}=7)$. Wingspan 10.9-13.2 mm. Frenulum with 3 acanthae. Antenna slightly thinner than that of male; antennal pecten present with three to five thin setae. Otherwise externally like males.

Female genitalia (n=1) (Fig. 16). As for H. kaupo, except without sclerotized area on posterior half of corpus bursae. 
Larva cases ( $\mathrm{n}=69)$. The case type is a burrito-shaped structure as for H. kaupo (4.4-7.3 $\mathrm{mm}$ in length). The background colour of the cases is greyish-brown.

ETYMOLOGY. From the Hawaiian kaikuono, or bay, referring to the collection place of the cases of this species at sea level.

BIOLOGY. Adults were reared from case-making larvae collected during the day in January on rocks covered with lichen at sea level. Larvae were reared on fish food and carrots.

DisTRIBUTION. Currently known only from the Hawaiian island of Molokai, and presumed to be endemic to Molokai.

REMARKS. The differences in wing size and forewing colouration and details of the genitalia are morphological characters useful in distinguishing $H$. kapakai as a distinct species. This species status is strongly supported by the divergence in two DNA fragments (see Table 1).

\section{Conclusion}

These three species represent the first descriptions of new species of Hyposmocoma to include any molecular data. Just as Zimmerman lamented the 'hopelessness' of sorting through the morphological diversity of this spectacular radiation, we demonstrate the importance of molecular data in discerning otherwise morphologically similar species. Our conclusions are based on an integrative taxonomic approach (Dayrat 2005; Will et al. 2005; Rubinoff 2006) using molecular divergence from more than one gene (Rubinoff et al. 2006), combined with ecological and morphological data in resolving complex species relationships in this group. The molecular phylogenetics of Hyposmocoma will be the subject of future research, but the level of genetic divergence in these three morphologically similar species is indicative of sibling species (Mayr 1963; Bickford $e t$ al. 2007) in which apparently closely similar taxa are in fact reproductively isolated. Estimates of interspecific genetic divergence in COI for other Microlepidoptera range from slightly less than $1 \%$ to nearly $4 \%$ (Sperling \& Hickey 1994; Landry et al. 1999; Rubinoff \& Powell 2004), suggesting that the Hyposmocoma sibling species studied here exhibit relatively high levels of interspecific divergence, perhaps as a result of lineage-specific rates of evolution and/or their insular distributions. Future integrative taxonomic research may reveal patterns of diversification important in understanding the nature of Hawaiian radiations.

\section{Acknowledgements}

We thank Betsy Gagné and Division of Forestry and Wildlife, Department of Land and Natural Resources for permits, L. Gordon, P. Welton, Haleakala National Park for permits and assistance in the field, Mandy Heddle and especially Will Haines for assistance with collecting. We thank C. Pong, T. Tengan, D. Nitta, and J. Winhall-Rice for assistance with rearing larvae, C. Pong and D. Nitta for molecular work, Samuel 'Ohukani 'ōhi'a Gon III for help with Hawaiian names, and L. Leblanc for parasitoid identification. This research was supported in part by grants from the National Geographic Society's Committee for Research and Exploration, and by the State of Hawaii's U.S. Fish and Wildlife Service State Wildlife Grant (T-3-P). P. Schmitz was supported by a Swiss National Science Foundation postdoctoral grant (PBGEA/119-332).

\section{References}

Bickford, D., Lohman, D.J., Sodhi, N.S., Ng, P.K.L., Meier, R., Winker, K., Ingram, K.K., \& Das, I. (2007) Cryptic species as a window on diversity and conservation. Trends in Ecology and Evolution, 22, 148-155.

Butler, A.G. (1881) On a collection of nocturnal Lepidoptera from the Hawaiian Islands. Annals and Magazine of Natu- 
ral History (V), 7, 392-408.

Butler, A.G. (1882) On a small collection of nocturnal Lepidoptera from the Hawaiian Islands. Transactions of the Entomological Society of London for 1882, 31-45.

Dayrat, B. (2005) Towards integrative taxonomy. Biological Journal of the Linnean Society, 85, 407-415.

Gillespie, R.G. \& Roderick, G.K. (2002) Arthropods on islands: Colonization, speciation, and conservation. Annual Review of Entomology, 47, 595-632.

Kaneshiro K.Y. (1997) R.C.L. Perkins' legacy to evolutionary research on Hawaiian Drosophilidae (Diptera). Pacific Science, 51, 450-461.

Landry, B., Powell, J.A. \& Sperling, F.A.H. (1999) Systematics of the Argyrotaenia franciscana (Lepidoptera: Tortricidae) Species Group: Evidence from Mitochondrial DNA. Annals of the Entomological Society of America, 92, 4046.

Mayr, E. (1963) Animal Species and Evolution. Harvard University Press.

Reed, R.D. \& Sperling F.A.H. (1999) The interaction of process partitions in phylogenetic analysis: An example of the swallowtailed butterfly genus Papilio. Molecular Biology and Evolution, 16, 286-297.

Rubinoff, D. (2006) DNA Barcoding evolves into the familiar. Conservation Biology, 20, 1548-1549.

Rubinoff, D. \& Haines, W.P. (2005) Web-spinning caterpillar stalks snails. Science, 30, 575.

Rubinoff, D. \& Haines, W.P. (2006) Hyposmocoma molluscivora Description. Science, 311, 1377.

Rubinoff, D. \& Powell, J. (2004) Conservation of fragmented small populations: endemic species persistence on California's smallest channel island. Biodiversity and Conservation, 13, 2537-2550.

Rubinoff, D, Cameron, S. \& Will, K. (2006) A genomic perspective on the shortcoming of mitochondrial DNA for "Barcoding" identification. Journal of Heredity, 97, 581-594.

Sperling F.A.H. \& Hickey, D.A. (1994) Mitochondrial DNA sequence variation in the spruce budworm species complex (Choristoneura: Lepidoptera). Molecular Biology and Evolution,11 656-665.

Swezey, O.H. (1946) New species of Hawaiian Lepidoptera. Proceedings of the Hawaiian Entomological Society, 12 , $625-628$.

Walsingham, L. (1907) Microlepidoptera. In: Sharp, D. (Ed.), Fauna Hawaiiensis, Vol.1. Cambridge University Press, pp. 469-759.

Will, K.W., Mishler, B.D. \& Wheeler, Q.D. (2005) The perils of DNA Barcoding and the need for integrative taxonomy. Systematic Biology, 54, 844-851.

Zimmerman, E.C. (1978) Microlepidoptera. In: Insects of Hawaii, Vol.9. The University Press of Hawaii, Honolulu, $1903 \mathrm{pp}$. 